\title{
Saúde bucal de crianças com microcefalia associada ao Zika vírus
}

Oral health of children with microcephaly associated with Zika vírus

Salud bucal de los niños con microcefalia asociada al virus del Zika

Hannah Pereira COSTA ${ }^{1}$

Kauana da Silva ANDRADE ${ }^{2}$

José Jhenikártery Maia de OLIVEIRA ${ }^{2}$

Fábio Victor DIAS SILVA ${ }^{2}$

Artemisa Fernanda Moura FERREIRA ${ }^{3}$

Camila Santos de Mattos BRITO ${ }^{3}$

Rosa Virginia Dutra de OLIVEIRA ${ }^{4}$

Andreia Medeiros Rodrigues CARDOSO 4

${ }^{1}$ Cirurgiã-Dentista formada pelo Centro Universitário de João Pessoa (UNIPÊ), 8053-000, João Pessoa (PB), Brasil

${ }^{2}$ Graduando(a) no Centro Universitário de João Pessoa (UNIPÉ), 8053-000, João Pessoa (PB), Brasil

${ }^{3}$ Professora Mestre do Curso de Odontologia do Centro Universitário de João Pessoa (UNIPÊ), 8053-000, João Pessoa (PB), Brasil

${ }^{4}$ Professora Doutora do Curso de Odontologia Centro Universitário de João Pessoa (UNIPÊ), 8053-000, João Pessoa (PB), Brasil

\section{Resumo}

Objetivo: descrever sobre as condições bucais das crianças com Microcefalia associada ao Zika vírus. Metodologia: Estudo transversal realizado com 13 crianças atendidas no projeto institucional e multidisciplinar "Atenção Integrada às crianças com microcefalia por Zika vírus" e seus respectivos cuidadores. Foi realizado entrevista com os cuidadores e de exame clínico bucal nas crianças, sendo coletados dados sobre características sociodemográficas e econômicas, hábitos de higiene, comportamentais e alimentares, assim como as características oclusais e os índices clínicos odontológicos (ISG, IPV e ceo-d). Os dados foram analisados de maneira descritiva e através do teste Wilcoxon no software Statistical Package for the Social Sciences, versão 20. Resultados: A maioria das crianças eram do sexo feminino (53,8\%), entre 24 e 35 meses (76,9\%) e a mãe era o principal cuidador (76,9\%). Em relação aos hábitos das crianças, $61,5 \%$ apresentavam alimentação semissólida, com frequência de escovação diária de duas vezes ou mais (46,2\%), utilizavam mamadeira $(76,9 \%)$ e chupeta (53,8\%). As crianças não apresentavam cárie, o ISG e IPV foram considerados satisfatórios. Além disso, 92,3\% das crianças rangiam os dentes durante a noite, $61,5 \%$ apresentavam mordida aberta anterior, sobressaliência aumentada $(84,6 \%)$ e cronologia de erupção alterada $(84,6 \%)$ Conclusão: As crianças apresentavam erupção dentária tardia, presença de facetas de desgastes, chave de canino com classificação I, mordida aberta anterior e sobressaliência aumentada. Além disso, possuíam frequência de escovação satisfatória, alimentações semissólida, usavam mamadeira e chupeta. A partir dos índices odontológicos, observou-se que as crianças apresentavam uma saúde bucal satisfatória.

Descritores: Saúde Bucal; Microcefalia; Zika Virus.

\section{Abstract}

Objective: to describe the oral conditions of children with microcephaly associated with Zika virus. Methodology: Cross-sectional study carried out with 13 children assisted in the institutional and multidisciplinary project "Integrated Care for children with microcephaly due to Zika virus" and their respective caregivers. Interviews were conducted with caregivers and a clinical oral exam was carried out on the children, with data on sociodemographic and economic characteristics, hygiene, behavioral and dietary habits, as well as occlusal characteristics and clinical dental indexes (ISG, IPV and ceo-d) being collected. The data were analyzed descriptively and using the Wilcoxon test in the Statistical Package for the Social Sciences software, version 20. Results: Most children were female (53.8\%), between 24 and 35 months $(76.9 \%)$ and the mother was the main caregiver (76.9\%). Regarding the children's habits, $61.5 \%$ had a semi-solid diet, with a daily brushing frequency of twice or more (46.2\%), used a bottle $(76.9 \%)$ and pacifier $(53.8 \%)$. The children did not present caries, the ISG and IPV were considered satisfactory. In addition, $92.3 \%$ of children gritted their teeth at night, $61.5 \%$ had an open anterior bite, increased overjet (84.6\%) and altered rash chronology (84.6\%) Conclusion: Children had a rash late dental, presence of wear facets, canine key with classification I, anterior open bite and increased overjet. In addition, they had a satisfactory brushing frequency, semi-solid food, used a bottle and used a pacifier. From the dental indexes, it was observed that the children had satisfactory oral health.

Descriptors: Oral Health; Microcephaly; Zika Virus.

\section{Resumen}

Objetivo: describir las condiciones bucales de los niños con microcefalia asociada al virus del Zika. Metodología: Estudio transversal realizado con 13 niños atendidos en el proyecto institucional y multidisciplinario "Atención integral a niños con microcefalia por virus Zika" y sus respectivos cuidadores. Se realizaron entrevistas con los cuidadores y se realizó un examen clínico bucal a los niños, con datos de características sociodemográficas y económicas, higiene, hábitos de comportamiento y dietéticos, así como características oclusales e índices clínico-odontológicos (ISG, IPV y ceo). -d) siendo recogido. Los datos se analizaron de forma descriptiva y mediante la prueba de Wilcoxon en el software Statistical Package for the Social Sciences, versión 20. Resultados: La mayoría de los niños eran mujeres (53,8\%), entre 24 y 35 meses $(76,9 \%)$ y la madre era la principal cuidadora. (76,9\%). En cuanto a los hábitos de los niños, el 61,5\% tenía alimentación semisólida, con una frecuencia de cepillado diario de dos o más (46,2\%), utilizaba biberón (76,9\%) y chupete $(53,8 \%)$. Los niños no presentaron caries, la ISG y la IPV se consideraron satisfactorias. Además, el 92,3\% de los niños apretaban los dientes por la noche, el $61,5 \%$ tenía una mordida anterior abierta, un resalte elevado (84,6\%) y una cronología de la erupción alterada (84,6\%) Conclusión: los niños tenían una erupción dental tardía, presencia de facetas de desgaste, canino clave con clasificación I, mordida abierta anterior y resalte aumentado. Además, tenían una frecuencia de cepillado satisfactoria, alimentos semisólidos, usaban biberón y usaban chupete. A partir de los índices dentales, se observó que los niños tenían una salud bucal satisfactoria.

Descriptores: Salud Bucal; Microcefalia; Virus Zika.

INTRODUÇÃO

A microcefalia é uma das condições de saúde que esteve em foco nos últimos anos, principalmente, devido as graves complicações neurológicas nos recém-nascidos. Segundo a Secretaria de Vigilância em Saúde (SVS), a identificação da microcefalia ocorre através da mensuração da circunferência occipito-frontal, medida padrão para obtenção do perímetro craniano, com valor menor ou igual a 31,5 centímetros, em recém-nascidos a termo para o 
sexo feminino e, 31,9 centímetros, para o sexo masculino ${ }^{1}$.

A microcefalia pode ser classificada como pré-natal e pós-natal, além de genética ou adquirida, a qual engloba os fatores externos potencialmente lesivos ao cérebro ${ }^{2}$. No caso das microcefalias congênitas adquiridas, os fatores etiológicos atuam durante 0 desenvolvimento do cérebro no período intrauterino e incluem as infecções maternas como, por exemplo, a infecção associada ao Zika vírus ${ }^{3}$.

Tem sido constatado que as pessoas com deficiência como as crianças com microcefalia associada ao Zika vírus apresentam um risco elevado para o desenvolvimento de patologias bucais como a cárie dentária e as doenças periodontais, considerando as suas próprias limitações, bem como a escassez dos serviços odontológicos adaptados a esta população $0^{4-6}$.

Além disso, é de suma importância que a atenção odontológica a essa população seja efetuada o mais cedo possível a fim de prevenir problemas futuros e de maiores proporções, bem como criar hábitos que irão perpetuar por toda a vida do paciente ${ }^{7}$.

Assim, essa pesquisa teve como objetivo descrever sobre as condições bucais das crianças com Microcefalia associada ao Zika vírus do Programa de Atenção Integrada na saúde bucal das crianças com Microcefalia por Zika vírus, bem como caracterizar seus hábitos de higiene, comportamental e alimentares das mesmas.

\section{MATERIAL E MÉTODO}

Trata-se de um estudo transversal, de abordagem quantitativa, com procedimentos descritivos e analíticos, realizado no Programa institucional e multidisciplinar "Atenção Integrada à Criança com Microcefalia por Zika vírus" de uma Instituição de Ensino Superior, localizada em João Pessoa - PB. O estudo foi aprovado com o CAAE 87216618.8.0000.5176 e parecer 2.703.631 pelo Comitê de Ética em Pesquisa (CEP) do UNIPÊ. A equipe foi calibrada de acordo com etapas teóricas e clínicas. $\mathrm{Na}$ etapa teórica foram discutidos, pontualmente, cada critério e código para realização do diagnóstico da cárie dentária e das alterações periodontais, enquanto que na fase clínica, realizou-se o exame clínico odontológico com registro do índice de ceo-d e de má oclusão em 10 crianças, de até 5 anos de idade, sem comprometimento neurológico, de um Centro de Referência em Educação Infantil (CREI) em João Pessoa - PB, Brasil.
Para avaliação da concordância foram montadas as matrizes e realizados os testes kappa interexaminador, comparando todos os dentes separadamente, sendo considerado um coeficiente Kappa 0,99 para ceo-d e 0,98 para má oclusão, respectivamente. Para verificar o instrumento de coleta de dados e treinamento da equipe de pesquisa, um piloto do estudo foi realizado com as 3 primeiras entrevistas com os cuidadores. Não houve nenhuma alteração no instrumento após o estudo piloto. A amostra foi constituída por 13 crianças, com faixa etária compreendida entre 0 a 48 meses, inscritas no Programa de Atenção à Criança com Microcefalia por Zika vírus e pelos seus respectivos responsáveis ou cuidadores, maiores de 18 anos de idade. Enquanto os critérios de exclusão estabelecidos foram: crianças com diagnóstico de microcefalia que não fossem associadas ao Zika vírus e, cuidadores, que fossem responsáveis pelas atividades diárias das crianças, durante um período inferior a três meses.

A coleta de dados ocorreu através de entrevista com o cuidador da criança e por meio do preenchimento da ficha clínica após o exame físico intrabucal da criança. Dessa forma, foram coletados dados demográficos, socioeconômicos das crianças e seus cuidadores, assim como os aspectos comportamentais da criança, como os hábitos alimentares, hábitos de higiene oral e hábitos deletérios. Durante o exame intrabucal nas crianças, foram observadas as inserções dos freios, o estado da mucosa, a oclusão, o tipo de arco dentário, a cronologia de erupção, a presença de desgastes dentais e as limitações de abertura bucal. Os exames clínicos foram realizados com o auxílio de espátulas de madeira, gazes, espelho bucal e sonda OMS, sob luz natural. A primeira etapa do exame verificou o número de dentes decíduos na cavidade bucal e a presença e o Índice de Placa Visível (IPV). O valor do IPV foi obtido em porcentagem, somando-se o número de superfícies com biofilme dividindo-se pelo total de superfícies examinada se multiplicadas por $100^{8}$. Além disso, foram preenchidos o Índice de dente decíduo cariado, extraído e obturado (ceo-d $)^{9}$, bem como o Índice de Sangramento Gengival (ISG), proposto por Ainamo e Bay ${ }^{10}$. Dessa forma, a avaliação do ISG foi adaptada pelo uso de quatro dentes índices 54, 61, 75 e 82 por meio do sangramento, após sondagem suave do sulco gengival, realizada nos dentes índices, nos quatro sítios de sondagem (vestibular, lingual/palatino, mesial e distal). 
Os dados foram analisados de forma descritiva, com medidas de distribuição absolutas e percentuais. Em seguida, foi realizada uma análise analítica para comparação dos dados antes e depois da intervenção, através do teste Wilcoxon, para comparar os dados de saúde bucal das crianças, através do software Statistical Package for the Social Sciences (SPSS), versão 20.

\section{RESULTADOS}

Este estudo foi realizado com 13 crianças com o diagnóstico de microcefalia por Zika vírus associado ao Zika vírus e pelos seus respectivos cuidadores. A maior parte das crianças com microcefalia foram do sexo feminino $(53,8 \%), 76,9 \%$ eram pardas e possuíam faixa etária entre 24 e 35 meses $(76,9 \%)$. Além disso, a entrevista foi realizada com os cuidadores, onde o principal responsável pela criança foi a mãe $(76,9 \%)$, $53,9 \%$ possuíam ensino médio completo, $61,5 \%$ não recebiam 0 Benefício de Prestação Continuada (BPC) e 69,2\% moravam em João Pessoa, capital da Paraíba, como descrito na Tabela 1.

Tabela 1. Caracterização demográfica e socieconômica da amostra. João Pessoa - PB, Brasil - 2018

\begin{tabular}{|c|c|}
\hline Variável & $\mathbf{N}(\%)$ \\
\hline \multicolumn{2}{|l|}{ Cidade onde vive } \\
\hline João Pessoa & $9(69,2 \%)$ \\
\hline Cabedelo & $1(7,7 \%)$ \\
\hline Bayeux & $1(7,7 \%)$ \\
\hline Santa Rita & $1(7,7 \%)$ \\
\hline Não informado & $1(7,7 \%)$ \\
\hline \multicolumn{2}{|l|}{ Localidade da residência } \\
\hline Urbana & $12(92,3 \%)$ \\
\hline Rural & $1(7,7 \%)$ \\
\hline \multicolumn{2}{|l|}{ Número de pessoas na residência } \\
\hline 1-3 pessoas & $4(30,8 \%)$ \\
\hline 4-6 pessoas & $7(53,8 \%)$ \\
\hline Mais de 10 pessoas & $2(15,4 \%)$ \\
\hline \multicolumn{2}{|l|}{ Sexo da criança } \\
\hline Masculino & $6(46,2 \%)$ \\
\hline Feminino & $7(53,8 \%)$ \\
\hline \multicolumn{2}{|l|}{ Faixa etária da criança } \\
\hline 12-23 meses & $1(7,7 \%)$ \\
\hline 24-35 meses & $10(76,9 \%)$ \\
\hline $36-47$ meses & $2(15,4 \%)$ \\
\hline \multicolumn{2}{|l|}{ Cor/Raça da criança } \\
\hline Branca & $3(23,1 \%)$ \\
\hline Parda/mestiça & $10(76,9 \%)$ \\
\hline \multicolumn{2}{|l|}{ Sexo do cuidador } \\
\hline Feminino & $13(100 \%)$ \\
\hline \multicolumn{2}{|l|}{ Parentesco do cuidador } \\
\hline Mãe & $10(76,9 \%)$ \\
\hline Nenhum & $2(15,4 \%)$ \\
\hline Não informado & $1(7,7 \%)$ \\
\hline \multicolumn{2}{|l|}{ Escolaridade do cuidador } \\
\hline Alfabetizado & $1(7,7 \%)$ \\
\hline Ensino fundamental incompleto & $3(23 \%)$ \\
\hline Ensino fundamental completo & $1(7,7 \%)$ \\
\hline Ensino médio incompleto & $1(7,7 \%)$ \\
\hline Ensino médio completo & $6(46,2 \%)$ \\
\hline Ensino superior completo & $1(7,7 \%)$ \\
\hline \multicolumn{2}{|c|}{ Conta com benefício oferecido pelo governo? } \\
\hline Sim & $4(30,8 \%)$ \\
\hline Não & $8(61,5 \%)$ \\
\hline Não informado & $1(7,7 \%)$ \\
\hline \multicolumn{2}{|l|}{ Tem trabalho renumerado atualmente? } \\
\hline Sim & $1(7,7 \%)$ \\
\hline Não & $10(76,9 \%)$ \\
\hline Não informado & $2(15,4 \%)$ \\
\hline \multicolumn{2}{|l|}{ Renda familiar da criança } \\
\hline Menos de um salário mínimo & $1(7,7 \%)$ \\
\hline De 1 a 2 salários mínimos & $10(76,9 \%)$ \\
\hline De 2 a 3 salários mínimos & $1(7,7 \%)$ \\
\hline Não informado & $1(7,7 \%)$ \\
\hline TOTAL & $13(100 \%)$ \\
\hline
\end{tabular}

Conforme a tabela 2, os 13 participantes da pesquisa faziam o uso de escova e dentifrício (100\%) para realizar a higiene bucal das crianças, possuíam uma frequência de escovação diária de duas vezes ou mais por dia $(46,2 \%)$, sendo considerado como um hábito satisfatório na higiene das crianças.

Em relação aos hábitos comportamentais das crianças, 76,9\% utilizavam mamadeira, $53,8 \%$ faziam o uso de chupeta e exclusivamente $23,1 \%$ tinham o hábito de succionar o dedo. $O$ hábito de ranger os dentes foi o mais frequente e em $92,3 \%$ dos casos esteve presente. Além disso, a predominância $(61,5 \%)$ da alimentação em consistência semissólida (Tabela 2).

Tabela 2. Distribuição das crianças com microcefalia por Zika vírus de acordo com os hábitos de higiene, comportamentais e hábitos alimentares. João Pessoa - PB, Brasil - 2018

\begin{tabular}{|c|c|}
\hline Variável & $\mathbf{N}(\%)$ \\
\hline \multicolumn{2}{|l|}{ Instrumentos utilizados para higiene } \\
\hline Escova e dentifrício & $13(100 \%)$ \\
\hline \multicolumn{2}{|l|}{ Frequência de escovação diária } \\
\hline Uma vez por dia & $2(15,4 \%)$ \\
\hline Duas vezes por dia & $6(46,2 \%)$ \\
\hline Três vezes por dia & $5(38,5 \%)$ \\
\hline \multicolumn{2}{|l|}{ Criança usa mamadeira? } \\
\hline Sim & $10(76,9 \%)$ \\
\hline Não & $3(23,1 \%)$ \\
\hline \multicolumn{2}{|l|}{ Criança usa chupeta? } \\
\hline Sim & $7(53,8 \%)$ \\
\hline Não & $6(46,2 \%)$ \\
\hline \multicolumn{2}{|l|}{ Criança faz sucção com o dedo? } \\
\hline Sim & $3(23,1 \%)$ \\
\hline Não & $10(76,9 \%)$ \\
\hline \multicolumn{2}{|l|}{ Criança faz interposição lingual? } \\
\hline Sim & $6(46,2 \%)$ \\
\hline Não & $7(53,8 \%)$ \\
\hline \multicolumn{2}{|l|}{ Criança faz interposição de lábio? } \\
\hline Sim & $5(38,5 \%)$ \\
\hline Não & $8(61,5 \%)$ \\
\hline \multicolumn{2}{|l|}{ Criança range os dentes enquanto morde? } \\
\hline Sim & $12(92,3 \%)$ \\
\hline Não & $1(7,7 \%)$ \\
\hline \multicolumn{2}{|l|}{ Cuidador recebeu orientação da dieta da } \\
\hline $\operatorname{Sim}$ & $11(84,6 \%)$ \\
\hline Não & $2(15,4 \%)$ \\
\hline \multicolumn{2}{|l|}{ Consistência da dieta da criança? } \\
\hline Sólida & $2(15,4 \%)$ \\
\hline Semissólida & $8(61,5 \%)$ \\
\hline Líquida & $2(15.4 \%)$ \\
\hline Semissólida e líquida & $1(7,7 \%)$ \\
\hline \multicolumn{2}{|l|}{ Instrumentos utilizados para oferecer alimento } \\
\hline Colher e copo & $4(30,8 \%)$ \\
\hline Sonda nasogástrica & $2(15,4 \%)$ \\
\hline Amamentação & $1(7,7 \%)$ \\
\hline Mamadeira e Seringa & $1(7,7 \%)$ \\
\hline Colher, copo e mamadeira & $4(30,8 \%)$ \\
\hline Colher, copo e seringa & $1(7,7 \%)$ \\
\hline \multicolumn{2}{|c|}{ Número de lanches (excluindo café, almoço e janta) } \\
\hline Até 2 & $4(30,8 \%)$ \\
\hline Acima de 2 & $8(61,5 \%)$ \\
\hline Não informado & $1(7,7 \%)$ \\
\hline TOTAL & $13(100 \%)$ \\
\hline
\end{tabular}

Entre as características bucais prevalentes, nas crianças com microcefalia associada ao Zika vírus, estão a baixa inserção do freio labial $46,2 \%$, o arco do tipo 2 de Baume 53,8\%, com ausência de diastemas na região anterior em ambas as arcadas. Além disso, a cronologia de erupção dos dentes decíduos apresentou-se discretamente atrasada para alguns elementos dentários, enquanto outros dentes estavam dentro do padrão de normalidade preconizado pela literatura. A maioria das crianças teve o início 
de erupção após os 12 meses de idade e, outro dado frequente, foram as facetas de desgastes em $61,5 \%$ dos casos (Tabela 3 ).

Tabela 3. Distribuição das crianças com microcefalia por Zika vírus de acordo com as características bucais. João Pessoa - PB, Brasil - 2018

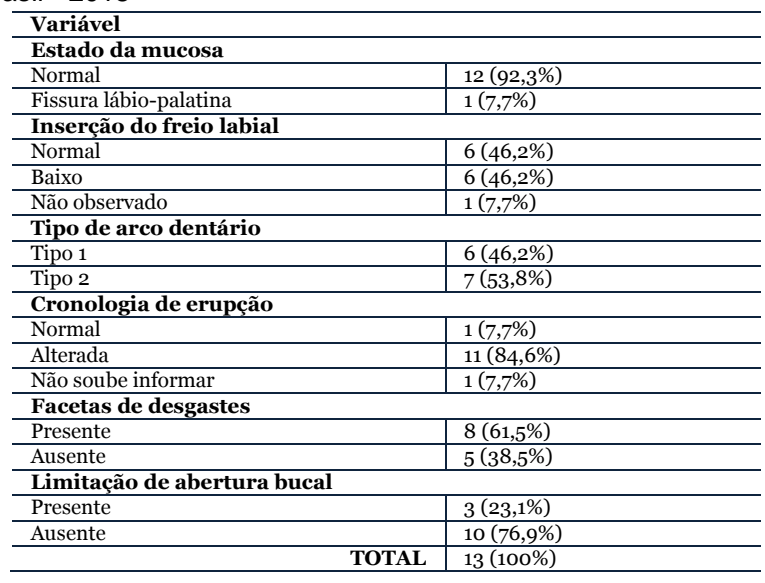

De acordo com a Tabela 4, foi observada uma sobressaliência aumentada em $84,6 \%$ das crianças com microcefalia e $61,5 \%$ possuíam mordida aberta anterior. Ainda neste contexto, a mordida cruzada posterior esteve presente, exclusivamente, em $7,7 \%$ das crianças.

Tabela 4. Distribuição das crianças com Microcefalia por Zika Vírus de acordo com as características oclusais. João Pessoa, PB, 2018.

\begin{tabular}{lc}
\hline Variável & N (\%) \\
\hline Chave de canino & $9(69,2 \%)$ \\
\hline Classe I & $3(23,1 \%)$ \\
Classe II & $1(7,7 \%)$ \\
Sem informação & $1(7,7 \%)$ \\
\hline Sobressaliência & $11(84,6 \%)$ \\
\hline Normal & $1(7,7 \%)$ \\
Aumentada & $8(61,5 \%)$ \\
Sem informação & $4(30,8 \%)$ \\
\hline Sobremordida & $1(7,7 \%)$ \\
\hline Aberta & $1(7,7 \%)$ \\
Profunda & $11(84,6 \%)$ \\
Sem informação & $1(7,7 \%)$ \\
\hline Mordida cruzada posterior & $13(100 \%)$ \\
\hline Presente & \\
Ausente & \\
Sem informação &
\end{tabular}

Como está apresentado na Tabela 5, $61,5 \%$ das crianças com microcefalia obtiveram o ISG entre 0-10. Desse modo, o ISG regular ou satisfatório é considerado um aspecto positivo, visto que essas crianças utilizavam medicamentos de uso sistêmico, no entanto, as orientações sobre a higiene bucal e a escovação supervisionada regularmente demonstraram a eficácia na manutenção da saúde bucal das crianças.

Tabela 5. Distribuição das crianças com microcefalia por Zika vírus de acordo com o cálculo do ISG. João Pessoa - PB, Brasil - 2018.

\begin{tabular}{l|c|c}
\hline Valores & Frequência & $\mathbf{N}(\%)$ \\
\hline $\mathbf{0 , 0}$ & 7 & $53,8 \%$ \\
\hline $\mathbf{6 , 2 5}$ & 1 & $7,7 \%$ \\
\hline $\mathbf{1 2 , 5 0}$ & 3 & $23,1 \%$ \\
\hline $\mathbf{1 8 , 7 5}$ & 2 & $15,4 \%$ \\
\hline TOTAL & 13 & $100 \%$ \\
\hline
\end{tabular}

Conforme demonstrado na Tabela 6, as crianças não apresentavam cárie dentária e o IPV foi coletado em dois momentos, um inicial e um final (Ti e Tf), onde foi observado uma diminuição do índice de 0,32 para 0,12, dado esse, favorável.

Tabela 6. Média e desvio-padrão dos índices ceo-d, ISG e IPV em crianças com Microcefalia por Zika Vírus. João Pessoa - PB, Brasil -2018

\begin{tabular}{l|l|l|l}
\hline & Tempo Inicial & Tempo Final & Valor de p \\
\hline ceo-d & 0,00 & 0,08 & 0,317 \\
\hline $\mathbf{C}$ & 0,00 & 0,08 & 0,317 \\
\hline $\mathbf{E}$ & 0,00 & 0,00 & 1,000 \\
\hline $\mathbf{O}$ & 0,00 & 0,00 & 1,000 \\
\hline IPV & 0,32 & 0,12 & 0,080 \\
\hline \multicolumn{2}{r}{ No período anterior a orientação }
\end{tabular}
motivação quanto a realização da higiene bucal das crianças, os cuidadores relataram que sentiam dificuldade em realizar a higiene bucal das mesmas, como também não sabiam a quantidade correta de creme dental e desconheciam sobre a importância de utilizar creme dental fluoretado. Além disso, relataram a dificuldade em ter que realizar esta atividade sozinhas.

DISCUSSÃo

Este estudo buscou descrever sobre as condições bucais das crianças com Microcefalia associada ao Zika vírus, uma vez que, esses aspectos ainda não estão bem definidos na literatura. A causalidade temporal entre o surto do Zika vírus e a prevalência de microcefalia no nascimento de crianças em estados endêmicos localizados, em sua maior parte, na região nordeste do Brasil, sugerem uma relação entre esses dois eventos epidemiológicos ${ }^{11}$.

Nesta pesquisa, as crianças com Microcefalia foram com maior frequência do sexo feminino $(53,8 \%)$, o que corrobora com o estudo realizado em Salvador - BA, o qual observou que $53,6 \%$ das crianças eram do sexo feminino, no entanto, a literatura não define a predominância de sexo específico para o diagnóstico da microcefalia ${ }^{12}$.

A maioria das crianças possuía uma faixa etária entre 24 e 35 meses $(76,9 \%)$, ou seja, nasceram entre novembro de 2015 e janeiro de 2016, o que coincide com a relação temporal do Zika vírus e a microcefalia, uma vez que, 0 surto ocorreu nesse período, correlacionando, desta maneira, com estudos anteriores que afirmam que a idade das crianças é compatível com o surto ${ }^{9,10}$. Além disso, a cor de pele predominante entre as crianças foi a parda e $76,9 \%$ dos cuidadores declararam essa etnia. Em concordância com o estudo anterior, a cor de predominância das crianças acometidas com a microcefalia também foi descrita como a parda $(56,10 \%)^{13}$.

A entrevista realizada com os cuidadores demonstrou que o principal responsável pela criança foi a mãe $(76,9 \%)$, isso também foi observado em estudo realizado com cuidadores de crianças com microcefalia em Maceió - AL, 
onde as mães $(77,7 \%)$ eram as cuidadoras primárias $^{14 .}$

Com referência ao grau de escolaridade do cuidador, foi observado que a maioria possuía ensino médio completo (53,9\%), assim como foi evidenciado em 2018 por Gonçalves et al. $^{12}$, onde $41,46 \%$ das mães também afirmaram ter ensino médio completo, sendo um indicador positivo, pois demonstra o acesso à educação básica.

Em contrapartida, o índice de Ensino Superior Completo encontrado foi baixo $(7,7 \%)$, o que é preocupante, uma vez que, pode interferir nas condições de vida das crianças, pois mostra que a maior parte dos cuidadores não tem qualificação para um vínculo empregatício com maior renda salarial. Ressalta-se que as condições socioeconômicas influenciam a saúde, a moradia, a cultura e as condições de vida, assim como a forma do cuidado prestado à pessoa com deficiência ${ }^{13}$.

$$
\text { Em relação as condições }
$$

sociodemográficas, $92,3 \%$ viviam em zona urbana e 69,2\% afirmaram morar na capital da Paraíba, João Pessoa, o que facilitava a locomoção desses cuidadores para os locais de reabilitação multiprofissional. Neste estudo, $53,8 \%$ possuíam sua residência com cobertura pelo Programa Saúde da Família, o que é considerado preocupante pela falta de acompanhamento dos Agentes Comunitários de Saúde no saneamento básico, em foco, neste caso, no controle do mosquito Aedes aegypti. Logo, parte da atenção à saúde dessas crianças é oriunda de instituições que oferecem reabilitação multiprofissional, como, por exemplo, o Programa de Atenção Integrada às crianças com Microcefalia por Zika vírus.

Segundo o número de pessoas que residem com as crianças, 53,8\% possuíam entre 4 a 6 pessoas em sua residência, em consonância com o estudo realizado em 2018 por Gonçalves et al. ${ }^{12}$, no qual as crianças conviviam em ambientes com mais de 3 pessoas $(43,90 \%)$. Com relação a renda familiar, a predominância foi de até 2 salários mínimos, onde grande parte das genitoras eram donas do lar e não possuíam emprego remunerado, de forma que a renda era exclusivamente paterna ou por doações de familiares.

Além disso, a maioria das mães deixou de trabalhar para cuidar de seus filhos após o nascimento, devido ao comprometimento neurológico destas crianças que necessitam de atenção total para realização das atividades diárias. Neste cenário, estão relacionadas as situações socioeconômica e educacional, onde quanto melhor a situação financeira $e$ educacional dos pais, maior será o estímulo para o crescimento e desenvolvimento da criança com microcefalia advinda da infecção materna por Zika vírus.

Foi observado que $61,5 \%$ não recebiam o Benefício de Prestação Continuada (BPC), o que não corrobora 0 estudo transversal realizado em 2020 por Garcia et al. ${ }^{15}$ no Centro de Referência em Neurodesenvolvimento, Assistência e Reabilitação de Crianças, localizado em São Luís - MA, onde 67,06\% das crianças recebiam o benefício assistencial do Instituto Nacional do Seguro Social (INSS).

A Lei 13.301/2016 garante 0 direito ao benefício de prestação continuada (BPC) temporário no valor de 1 salário mínimo mensal, pelo período máximo de 3 anos, na condição da criança vítima de microcefalia oriunda de doenças transmitidas pelo Aedes aegypti. Além disso, 0 BPC pode continuar, independentemente da idade, de acordo com a renda familiar ${ }^{16}$.

Neste estudo, os aspectos bucais mais frequentes foram a mordida aberta anterior $(61,5 \%)$, os desgastes dentais $(92,3 \%)$, a alteração na cronologia eruptiva da dentição decídua (84,6\%), assim como o uso de chupetas $(52,8 \%)$ e da mamadeira $(76,9 \%)$. De acordo com Cota et al. ${ }^{17}$, em estudo realizado em 2020, os achados bucais mais prevalentes em crianças com a síndrome congênita de Zika foram o bruxismo (58,3\%), a erupção dentária tardia $(58,3 \%)$ e o biofilme visível $(66,6 \%)$. Além disso, foi observado que 41,6 faziam o uso de chupetas e 16,6\% apresentavam mordida aberta anterior. Em relação aos hábitos alimentares, a mamadeira noturna $(66,6 \%)$ foi considerada a mais frequente.

A predominância $(61,5 \%)$ da alimentação em consistência semissólida, pode ser devido ao fato da disfagia orofaríngea, presente em condições deste comprometimento neurológico.

A frequência de facetas de desgaste está em consonância com o estudo realizado em 2010 por $\mathrm{Du}$ et $\mathrm{al}^{18}{ }^{18}$, onde o desgaste dentário foi maior entre crianças com paralisia cerebral do que na população em geral, atribuindo-se aos hábitos parafuncionais como, por exemplo, o bruxismo.

Entre as características bucais das crianças, observou-se que $46,2 \%$ possuíam baixa inserção do freio labial e $84,6 \%$ das crianças tiveram a cronologia eruptiva alterada, com início de erupção após os 12 meses de idade. Esses achados corroboram com o estudo transversal realizado com 61 crianças com microcefalia associada ao Zika vírus, atendidas 
em um Hospital, em Salvador, onde as crianças apresentaram erupção dentária tardia $(61,7 \%)$ e baixa inserção do freio labial $(64 \%)^{19}$. Dessa forma, a média para o início do período eruptivo, em ambos os sexos, é de 8 meses, sendo uma preocupação para os familiares e cuidadores, pelos problemas funcionais que a erupção dentária tardia pode promover ${ }^{20,21}$.

As crianças com microcefalia possuem uma tendência maior para desenvolver má oclusão na dentição permanente, devido ao seu alto comprometimento neurológico, assim como ocorre nas crianças com paralisia cerebral ${ }^{22,23}$. Não foram encontrados estudos que avaliaram a presença de má oclusão em crianças com microcefalia pelo Zika vírus, no entanto, esse padrão de sobressaliência aumentada, hipotonia labial, presença de mordida aberta anterior, assim como outras características é localizado em crianças que tem microcefalia. $O$ que nos mostra que estas crianças com microcefalia possuem uma tendência alta de desenvolver má oclusão na dentição permanente, devido ao seu alto comprometimento neurológico, assim como ocorre nas crianças com paralisia cerebral.

Em relação a cárie dentária, as crianças não apresentavam processos cariosos, em concordância com o estudo realizado com 12 crianças, na faixa etária de 36 a 40 meses, o constatou que apenas 1 criança apresentava cárie $(8,3 \%)^{16}$. Dessa forma, ressalta-se que, neste estudo, as crianças apresentavam dentes recém-erupcionados e o percentual de aumento de cárie $(0,08 \%)$ encontrado foi baixo, o que é favorável frente as atividades educativas sobre a correta realização da higiene oral que 0 programa realizava com as crianças e os cuidadores.

Em relação ao ISG, $61,5 \%$ das crianças com microcefalia obtiveram o ISG de 0 a 10. Não foram encontrados estudos recentes sobre a condição de saúde periodontal de crianças com microcefalia, mas, neste contexto, o estudo transversal de Cardoso et al. ${ }^{24}$, realizado em 2017, observou que o ISG encontrado em 40 crianças com paralisia cerebral, de 2 a 6 anos de idade, correspondeu a $72,7 \%$.

Uma característica incomum que acontece nas crianças com microcefalia é a baixa incidência de gengivite, embora a condição periodontal de crianças com paralisia cerebral apresente alta prevalência de alterações. Um fator relacionado foi o uso de medicamentos anticonvulsivantes, utilizados pelas crianças com paralisia cerebral, pois, ele induz a hiperplasia gengival, constituindo um fator predisponente para as doenças periodontais ${ }^{25}$.
Todos os cuidadores relataram sentir dificuldade em realizar a escovação das crianças devido à limitação de abertura bucal, falta de colaboração e reflexo de mordida, assim como, a carência de informações sobre os cuidados de saúde bucal. Esses dados corroboram com 0 estudo realizado com cuidadores de crianças com deficiência motora, em João Pessoa - PB, Brasil ${ }^{26}$.

Ainda não são suficientes os conhecimentos sobre a Síndrome Congênita do Zika Vírus, tanto sobre sua evolução natural, como seus fatores de risco ou associados. Todavia, a partir do alcance dos objetivos do presente estudo pode-se afirmar a necessidade de intervenção por parte dos profissionais de saúde e familiares que enfrentam esta realidade. Pela complexidade dos casos, a assistência dessas crianças deve ser realizada por uma equipe multidisciplinar, incluindo pediatra, neurologistas, odontólogos, enfermeiros e profissionais de estimulação precoce, destacando fisioterapeuta, terapeuta ocupacional e fonoaudiólogo.

O Programa de Atenção Integrada à Criança com microcefalia por Zika Vírus foi realizado de forma individual, periódica, com eliminação das necessidades básicas em saúde bucal e participação ativa dos cuidadores, dentro de um processo de aprendizagem horizontal.

Desse modo, observou-se que as ações em saúde bucal desenvolvidas no Programa de Atenção Integrada às crianças com microcefalia por Zika vírus, foram efetivas para a manutenção de saúde bucal destas crianças.

Neste âmbito, propõem-se a realização de atividades de estimulação a crianças com microcefalia relacionada ao Zika vírus, com foco nos principais déficits, com o propósito de reduzir atrasos no crescimento e desenvolvimento. Assim como também dar relevância as condições de saúde bucal das crianças, destinando-se a melhorar as expectativas e qualidade de vida para as mesmas, para que assim reflitam positivamente nas âmbito familiar e social.

CONCLUSÃO

As condições bucais mais prevalentes nas crianças com microcefalia associada ao Zika vírus foram a erupção dentária tardia, a presença de facetas de desgastes, chave de canino com classificação I, mordida aberta anterior e sobressaliência aumentada.

De acordo com os hábitos de higiene bucal, alimentares e comportamentais, as crianças possuíam uma frequência de escovação diária de duas vezes ou mais. A 
maioria apresentava uma alimentação semissólida, utilizavam mamadeira e faziam o uso de chupeta.

As crianças não possuíam cárie no início do projeto, ao final do mesmo, o índice de ceo-d permaneceu baixo. O ISG e IPV coletados foram baixos, sendo observado uma diminuição do IPV ao final do projeto. Não foram observadas diferenças significativas entre os valores do ceo-d e IPV.

\section{REFERÊNCIAS}

1. Ministério da Saúde (BR). Dengue, Chikungunya e Zika. Brasília (DF): 2016.

2. WHO. World Health Organization. Assessment of infants with microcephaly in the context of Zika virus. Disponível em: http://www.who. int/csr/resources/publications/zika/ assessmentinfants/en/.

3. Brunoni D, Blascovi-Assis SM, Osório AAS, Seabra AG, Amato CAH, Teixeira MCTV et al. Microcefalia e outras manifestações relacionadas ao vírus Zika: impacto nas crianças, nas famílias e nas equipes de saúde. Cienc saúde colet. 2016;21(10): 3297-302.

4. Santos JS, Valle DA, Palmier AC, do Amaral $\mathrm{JH}$, de Abreu $\mathrm{MH}$. Availability of hospital dental care services under sedation or general anesthesia for individuals with special needs in the Unified Health System for the State of Minas Gerais (SUS-MG), Brazil. Cien Saude Colet. 2015;20(2):515-24.

5. Kohashi BSO, Ribeiro EOA, Soares KS, Prestes GBR. Abordagem preventiva e educativa em paciente odontológico com microcefalia associada ao Zika virus: relato de caso. Arch Health Invest. 2019;8(1):33-8.

6. Leite CN, Varellis MLZ. Microcefalia e a Odontologia Brasileira/Microcephaly and brazilian dentistry/Microcefalia y la odontología brasileña. J Health NPEPS. 2016;1 (2):297-304.

7. Hasan $S$, Saeed $S$, Panigrahi R, Choudhary P. Zika Virus: A Global Public Health Menace: A Comprehensive Update. J Int Soc Prev Community Dent. 2019;9(4):316-27.

8. Cardoso L, Rosing CK, Kramer PF. Doença periodontal em crianças - levantamento epidemiológico através dos índices de placa visível e de sangramento gengival. JBP: j bras odontopediatr odontol bebe. 2000;3(11):55-61.

9. World Health Organization. Oral health surveys: basic methods. 2013;5:1-125.

10. Ainamo J, Bay I. Problems and proposals for recording gingivitis and plaque. Int Dent $\mathrm{J}$. 1975;25(4): 229-35.

11. Oliveira WK, Cortez-Escalante, J, Oliveira WTGH et al. Increase in Reported Prevalence of Microcephaly in Infants Born to Women Living in Areas with Confirmed Zika Virus
Transmission During the First Trimester of Pregnancy - Brazil, 2015. MMWR Morb Mortal Wkly Rep. 2016;65:242-47.

12. Gonçalves AE, Tenório SDB, Ferraz PCS. Aspectos socioeconômicos dos genitores de crianças com microcefalia relacionada ao Zika vírus. Rev Pesqui Fisioter. 2018;8(2):155-66.

13. Maguina C, Galan-Rodas E. El virus Zika: una revisión de literatura. Acta méd peruana. 2016; 33(1):35-41.

14. Sarmento-Omena ARA, Silva LB, Cota ALS, Ribeiro CMB. Perception and knowledge about bucal health of caregivers of children with microcephaly. Rev Gaúch Odontol. 2019;67: 1-9.

15. Garcia ER, Bezerra SS, Reis LIF, Azevedo SS, Viana ES, Silva JWV et al. Qualidade de vida de cuidadores de crianças com microcefalia/Quality of life of careers of children with microcephaly. Braz J of Develop. 2020; 6(1):5040-55.

16. IOB. Garantidos benefício a criança com microcefalia e licença-maternidade á mãe de criança com sequelas causadas pelo Aedes aegypti [Internet]. 2016. Disponível em: http://www.seteco.com.br/garantidos-beneficiocrianca-com-microcefalia-e-licencamaternidade -mae-de-crianca-com-sequelas-causadaspeloaedes-aegypti/.

17. Cota ALS, Lopes MGM, Pio IM, Oliveira MJ, Rodrigues DF, Panjwan CMBRG. Oral findings in children with congenital zika syndrome: a case series. Saúde e Pesqui. 2020;13(1): 133-42.

18. Du RY, Mcgrath C, Yiu CK, King NM. Oral health in preschool children with cerebral palsy: a case-control community-based study. Int $\mathrm{J}$ Paediatr Dent. 2010;20(5):330-35.

19. Ribeiro RA, Mattos A, Meneghim MC, Vedovello SAS, Borges TMD, Santamaria M. Oral and maxillofacial outcomes in children with microcephaly associated with the congenital Zika syndrome. Eur J Orthod. 2021;43(3): 346-52.

20. Brandão CF, Rocha MCBSD. Cronologia e sequência de erupção dos dentes decíduos em crianças de 0 a 42 meses. JBP rev Ibero-am odontopediatr odontol bebê. 2004;7(40)528-35.

21. Santos AG, da Rocha GO, de Andrade JB. Occurrence of the potent mutagens 2nitrobenzanthrone and 3-nitrobenzanthrone in fine airborne particles. Sci Rep. 2019;9(1):1-13.

22. Miamoto CB, Ramos-Jorge ML, Ferreira MC, Oliveira Md, Vieira-Andrade RG, Marques LS. Dental trauma in individuals with severe cerebral palsy: prevalence and associated factors. Braz Oral Res. 2011;25(4):319-23.

23. de Carvalho RB, Mendes RF, Prado RR Jr, Moita Neto JM. Oral health and oral motor function in children with cerebral palsy. Spec Care Dentist. 2011;31(2):58-62. 
24. Cardoso AMR, Medeiros MM, Martins ML, Padilha WWN, Cavalcanti AL. Bucal condition of institutionalized brazilian children and adolescents with cerebral palsy. Rev Port Estomatol Med Dent Cir Maxilofac. 2017;58(2): 105-10.

25. Guerreiro PO, Garcias GL. Diagnóstico das condições de saúde bucal em portadores de paralisia cerebral do município de Pelotas. Ciênc saúde coletiva. 2009;14(5):1939-46.

26. Cardoso AMR, Brito DBA, Alves VF, Padilha WWN. O acesso ao cuidado em saúde bucal para crianças com deficiência motora: perspectivas dos cuidadores. Pesq bras odontopedatria clin integr. 2011;11(4):593-99.

\section{CONFLITO DE INTERESSES}

Os autores declaram não haver conflitos de interesse

AUTOR PARA CORRESPONDÊNCIA

\section{Hannah Pereira Costa}

BR $230-\mathrm{Km} 22$

58053-000 João Pessoa - PB, Brasil

E-mail: hannaahp@gmail.com 